\title{
BMJ Open A coronary heart disease prediction model: the Korean Heart Study
}

\author{
Sun Ha Jee, ${ }^{1}$ Yangsoo Jang, ${ }^{2}$ Dong Joo Oh, ${ }^{3}$ Byung-Hee Oh, ${ }^{4}$ Sang Hoon Lee, ${ }^{5}$ \\ Seong-Wook Park, ${ }^{6}$ Ki-Bae Seung, ${ }^{7}$ Yejin Mok, ${ }^{1}$ Keum Ji Jung, ${ }^{1}$ Heejin Kimm, ${ }^{,}$ \\ Young Duk Yun, ${ }^{8}$ Soo Jin Baek, ${ }^{8}$ Duk Chul Lee, ${ }^{9}$ Sung Hee Choi, ${ }^{10}$ Moon Jong Kim, ${ }^{11}$ \\ Jidong Sung, ${ }^{12}$ BeLong Cho, ${ }^{13}$ Eung Soo Kim, ${ }^{14}$ Byung-Yeon Yu, ${ }^{15}$ Tae-Yong Lee, ${ }^{16}$ \\ Jong Sung Kim, ${ }^{17}$ Yong-Jin Lee, ${ }^{18}$ Jang-Kyun Oh, ${ }^{19}$ Sung Hi Kim, ${ }^{20}$ Jong-Ku Park, ${ }^{21}$ \\ Sang Baek Koh, ${ }^{22}$ Sat Byul Park, ${ }^{23}$ Soon Young Lee, ${ }^{24}$ Cheol-In Yoo, ${ }^{25}$ \\ Moon Chan Kim, ${ }^{26}$ Hong-Kyu Kim, ${ }^{27}$ Joo-sung Park, ${ }^{28}$ Hyeon Chang Kim, ${ }^{29}$ \\ Gyu Jang Lee, ${ }^{30}$ Mark Woodward ${ }^{31,32,33}$
}

To cite: Jee SH, Jang Y, Oh DJ, et al. A coronary heart disease prediction model: the Korean Heart Study. BMJ Open 2014;4:e005025. doi:10.1136/bmjopen-2014005025

- Prepublication history and additional material is available. To view please visit the journal (http://dx.doi.org/ 10.1136/bmjopen-2014005025).

SHJ and YJ equally contributed.

Received 12 February 2014 Revised 11 April 2014 Accepted 23 April 2014

\section{CrossMark}

For numbered affiliations see end of article.

Correspondence to Dr Sun Ha Jee; jsunha@yuhs.ac

\section{ABSTRACT}

Objective: The objectives of this study were to develop a coronary heart disease (CHD) risk model among the Korean Heart Study (KHS) population and compare it with the Framingham CHD risk score.

Design: A prospective cohort study within a national insurance system.

Setting: 18 health promotion centres nationwide between 1996 and 2001 in Korea.

Participants: 268315 Koreans between the ages of 30 and 74 years without CHD at baseline.

Outcome measure: Non-fatal or fatal CHD events between 1997 and 2011. During an 11.6-year median follow-up, $2596 \mathrm{CHD}$ events (1903 non-fatal and 693 fatal) occurred in the cohort. The optimal CHD model was created by adding high-density lipoprotein (HDL)cholesterol, low-density lipoprotein (LDL)-cholesterol and triglycerides to the basic CHD model, evaluating using the area under the receiver operating characteristic curve (ROC) and continuous net reclassification index (NRI).

Results: The optimal CHD models for men and women included $\mathrm{HDL}$-cholesterol (NRI $=0.284$ ) and triglycerides (NRI=0.207) from the basic CHD model, respectively. The discrimination using the $\mathrm{CHD}$ model in the Korean cohort was high: the areas under ROC were $0.764(95 \% \mathrm{Cl} 0.752$ to 0.774$)$ for men and $0.815(95 \% \mathrm{Cl} 0.795$ to 0.835$)$ for women. The Framingham risk function predicted 3-6 times as many CHD events than observed. Recalibration of the Framingham function using the mean values of risk factors and mean CHD incidence rates of the KHS cohort substantially improved the performance of the Framingham functions in the KHS cohort.

Conclusions: The present study provides the first evidence that the Framingham risk function overestimates the risk of $\mathrm{CHD}$ in the Korean population where $\mathrm{CHD}$ incidence is low. The Korean CHD risk model is well-calculated alternations which can be used to predict an individual's risk of $\mathrm{CHD}$ and provides a useful guide to identify the groups at high risk for $\mathrm{CHD}$ among Koreans.

\section{Strengths and limitations of this study}

- Coronary risk scores, which utilise data on multiple risk factors, are ideal for making rational decisions regarding the distribution of scarce health service resources. The Framingham risk score overestimates the coronary risk in other populations, such as contemporary populations in Europe.

- There are no data on whether the Framingham risk score overestimates the coronary risk in Korea.

- Fatal and non-fatal (hospitalised) events among the study cohort were identified from insurance claims which were reported to the National Health Insurance System between the date of examination and 31 December 2011, giving a median follow-up of 11.6 years.

- This is an unusually large study with over 200000 participants.

- The limitations of this study include possible measurement errors and the non-random sample used.

\section{INTRODUCTION}

In 2008, cardiovascular disease (CVD) accounted for $30 \%$ of total global deaths, while $80 \%$ of CVD deaths occurred in lowincome and middle-income countries. Of these deaths, an estimated 7.3 million were due to coronary heart disease (CHD) and 6.2 million were due to stroke. ${ }^{1}$ In Korea, CVD is now one of the leading preventable causes of death in Korea, causing $22 \%$ of all deaths in 2011. ${ }^{2}$

CHD risk scores, which utilise data on multiple risk factors, are ideal for making rational decisions regarding the distribution of scarce health service resources. The Framingham CHD Risk Score (FRS), developed in a middle-class population in 
Massachusetts, is the most commonly used CHD risk score worldwide. However, in recent years, several investigators have demonstrated that the FRS overestimates the coronary risk in other populations, such as contemporary populations in Europe $^{3-5}$ and Asia, ${ }^{6}$ including Korea, ${ }^{7}$ while others have suggested that additional risk factors may add to the predictability of those included in the FRS. ${ }^{8-10}$ Although some studies have investigated this issue in Asian populations, ${ }^{8}{ }^{9}$ none had a follow-up of over 10 years.

To date, no national CHD risk score has been developed for Korea, despite the existence of some very large cohort studies with the potential to produce more reliable estimates of risk associations than have previously been possible.

The objectives of this study were, thus, to evaluate the applicability of the Framingham risk function ${ }^{11}$ in the Korean Heart Study (KHS) population, and to develop a Korean CHD risk score.

\section{METHOD}

\section{Study population}

KHS included 430920 individuals (266 782 men and 164138 women) who had voluntarily undergone private health examinations in 18 centres located in the capital and six provinces in South Korea between 1996 and 2004. A full description of KHS has been previously published. ${ }^{12} 13$

To develop a 10-year CHD risk prediction model, the baseline period used for this study was between 1996 and 2001; however, since we have followed them until December 2011 this gives at least 10 years of potential follow-up for everyone included (figure 1). Sixteen thousand five hundred and seventy-eight participants who reported of having cancer, liver disease, CVD or a respiratory disease at, or prior to, the initial visit were excluded. Also, 5408 participants with missing information on blood pressure, total serum cholesterol, fasting serum glucose, smoking status or body mass index (BMI), or who had an extremely low BMI $\left(<16 \mathrm{~kg} / \mathrm{m}^{2}\right)$

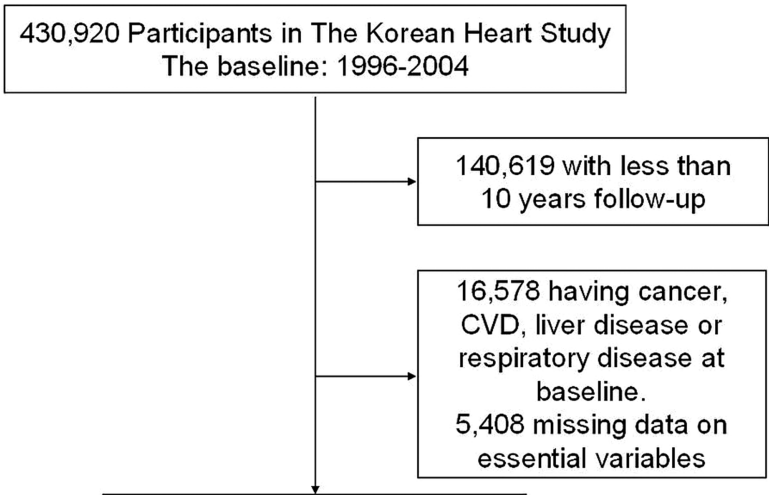

268,315 Participants Followed until December 2011

Figure 1 Defining the study population. or height $(\leq 1.30 \mathrm{~m})$ were excluded. The final study participants were 268315 individuals.

\section{Data collection}

Data files were collected from centres that maintained electronic databases, and manual data coding was performed by trained personnel for data collected from centres that kept paper records. Smoking habits (current, former or never smoking) was ascertained from the questionnaires. Either registered nurses or blood pressure technicians measured blood pressure using a standard mercury sphygmomanometer. For clinical chemistry assays, serum was separated from peripheral venous blood samples that were obtained from each participant after $12 \mathrm{~h}$ of fasting and was stored at $-70^{\circ} \mathrm{C}$. Biomarkers, such as fasting glucose and lipid profiles, were measured using the Histachi-7600 analyser (Hitachi Ltd, Tokyo, Japan). Details on quality control were published previously. ${ }^{12}$

In 2006, the Korean Association of Quality Assurance for Clinical Pathology conducted a nationwide study of interlaboratory agreement, and the Department of Clinical Pathology at the Asan Medical Center was in charge of the analysis. After receiving written permission, we reviewed interlaboratory correlations for the participating centres. The interlaboratory correlation coefficients for all measured variables exceeded $0.95 .{ }^{12}$

\section{Outcome variables}

Fatal and non-fatal (hospitalised) events among the study cohort were identified from insurance claims which were reported to the National Health Insurance System (NHIS) between the date of examination and 31 December 2011, giving a median follow-up of 11.6 years. Since NHIS is a national organisation covering all of Korea's population, this should provide a complete event ascertainment.

'Hard' CHD events, comprising acute myocardial infarction, sudden death and other coronary deaths, were included in our study outcome variable. ${ }^{11}$ We ascertained non-fatal CHD events, defined according to the International Classification of Diseases 10th Revision (acute myocardial infarction, code I21), from health insurance claims data from the NHIS. For fatal CHD events, deaths from death records were collected. Death certificates from the National Statistical Office were identified via identification numbers, which are assigned to citizens at birth.

A validation study was conducted by 20 internists from the Korean Society of Cardiology in 2009. ${ }^{14}$ For the participants who provided written permission for the use of their personal information, $673 \mathrm{CHD}$ events between 1994 and 2007 were confirmed with individual hospital medical records, showing that $73 \%$ of designated myocardial infarctions were valid. The validation study was updated in 2013 with a value of $93 \% .^{15}$ The validation study on mortality data has not been conducted. 


\section{Statistical analysis}

To develop the risk score, an a priori decision was made to emulate the most commonly used version of the FRS $^{11}$ as far as possible. Thus, age, blood pressure, total and high-density lipoprotein-cholesterol (HDL-C), diabetes and smoking were considered for inclusion in the Korean CHD risk score (KRS). Furthermore, blood pressure, total and HDL-C were analysed in the same ordinal groups as in FRS, except that blood pressure was grouped according to the most recent (7th) guidelines of the Joint National Committee on Hypertension. ${ }^{16}$ Contemporary guidelines ${ }^{17}$ were used to define diabetes as self-reported or fasting glucose $>=126 \mathrm{mg} / \mathrm{dL}$. In addition, triglycerides and low-density lipoprotein (LDL)-cholesterol were considered for inclusion in the Korean risk score, in place of HDL-C, as was an extension of the definition of smoking status to include former smoking. Another a priori decision was to develop separate risk models for men and women, where, unlike the FRS, the same variables were to be used for each sex. This is thought to be the most sensible for practical applications.

To decide on what factors should enter the risk score, Cox proportional hazards regression models were fitted first to a basic set of classical risk factors: age, blood pressure, total cholesterol (TC), smoking and diabetes. Further models added, one-at-a-time, were HDL-C, LDL-cholesterol and triglycerides to this basic set. The final model was prespecified to be that with the best discrimination and risk classification of the four, averaged across the sexes. Discrimination was assessed by the cstatistic for survival data ${ }^{18} 19$ and other models were compared, for risk classification, with the basic model using the continuous form of the net reclassification index (NRI) for 10-year risk of CHD.

From the final model, the KRS was derived using standard methods. ${ }^{19}$ Its calibration was tested by dividing participants, within each sex, into tenths of predicted risk and using the Hosmer-Lemeshow, calibration and reclassification were carried out after splitting the data randomly into $50 \%$ development and $50 \%$ validation samples. ${ }^{20}$

\section{Comparison with the Framingham score}

We compared the regression coefficients from a Cox proportional hazard model, fitted to the KHS, with the same variables as in the FRS and the regression coefficients in the published account of the FRS ${ }^{11}$ using Wald tests. We recalibrated Framingham to the KHS population $^{19}$ and compared this to the KRS. All analyses were conducted using SAS, V.9.1.2 (SAS Institute Inc, Cary, North California, USA).

\section{RESULTS}

\section{Baseline risk factors and CHD incidence rates}

After excluding participants with missing values for any of the FRS risk factors, 268315 individuals (164005 men and 104310 women) were included in these analyses (table 1 ). These were largely middle aged at enrolment (mean age 45.8 years in men and 47.6 years in women). Those excluded due to missing values did not differ from those included, by age and sex. The mean levels of BMI and LDL-cholesterol were similar in both sexes. However, smoking was prevalent in men but uncommon in women. Similar prevalence rates for high TC and LDL-cholesterol were observed in men and women. The prevalence of reduced HDL-C and diabetes was higher in men than in women (table 2).

During an 11.6-year median follow-up, 2596 CHD events (1903 non-fatal and 693 fatal) occurred in the cohort. The average 10-year risk for CHD was $1.03 \%$ for men and $0.40 \%$ for women. Summary statistics of person-years of follow-up and CHD events by baseline risk factor level, and overall, within sex, are shown in table 2.

Tables 3 (men) and 4 (women) show the HR for each level of each prognostic factor, compared to its reference. As expected, in the 10-year predictions of CHD, all five predictors in the basic model (age, blood pressure, TC, smoking and diabetes) were statistically significant in both men and women. Models 1, 2 and 3 added HDL-C, LDL-cholesterol and triglycerides, respectively, to the basic model. Among these models, model 1 was the best discriminating model (area under the curve $($ AUC $)=0.764)$ for men and also the model with best reclassification of risk $(\mathrm{NRI}=0.284)$ compared with the

Table 1 Baseline characteristic of study participants, 1996-2001, the Korean Heart Study

\begin{tabular}{lll}
\hline & Men & Women \\
\hline $\mathrm{N}$ & 164005 & 104310 \\
& Mean $\pm \mathrm{SD}$ & Mean $\pm \mathrm{SD}$ \\
Age, years & $45.8 \pm 9.4$ & $47.6 \pm 10.0$ \\
Body mass index, $\mathrm{kg} / \mathrm{m}^{2}$ & $23.8 \pm 2.8$ & $23.2 \pm 3.1$ \\
Systolic blood pressure, $\mathrm{mm} \mathrm{Hg}$ & $123.3 \pm 16.7$ & $121.0 \pm 19.6$ \\
Diastolic blood pressure, $\mathrm{mm} \mathrm{Hg}$ & $78.3 \pm 11.6$ & $75.3 \pm 11.8$ \\
Total cholesterol, $\mathrm{mg} / \mathrm{dL}$ & $194.5 \pm 34.8$ & $195.1 \pm 37.4$ \\
HDL-cholesterol, $\mathrm{mg} / \mathrm{dL}$ & $47.9 \pm 10.6$ & $54.5 \pm 12.7$ \\
LDL-cholesterol, $\mathrm{mg} / \mathrm{dL}$ & $118.4 \pm 32.2$ & $118.9 \pm 33.6$ \\
Triglyceride, $\mathrm{mg} / \mathrm{dL}$ & $148.2 \pm 87.1$ & $113.3 \pm 67.5$ \\
Fasting glucose, $\mathrm{mg} / \mathrm{dL}$ & $97.1 \pm 24.2$ & $93.6 \pm 20.6$ \\
\hline & $\%$ & $\%$ \\
\hline Smoking status & & \\
Ex-smoker & 23.0 & 4.0 \\
Current smoker & 53.0 & 5.1 \\
Diabetes* & 8.4 & 6.0 \\
Medication & 1.9 & 1.6 \\
Hypertension $\dagger$ & 28.6 & 24.7 \\
Medication & 4.4 & 5.3 \\
\hline Diabetes was defined as & &
\end{tabular}

${ }^{*}$ Diabetes was defined as fasting serum glucose greater than $126 \mathrm{mg} / \mathrm{dL}$ or diabetic treatment history.

†Hypertension was defined as systolic blood pressure greater than $140 \mathrm{~mm} \mathrm{Hg}$ or diastolic blood pressure greater than $90 \mathrm{~mm} \mathrm{Hg}$ or medication.

HDL, high-density lipoprotein; LDL, low-density lipoprotein. 
Table 2 Baseline risk factors, person-years of follow-up and CHD events in men and women in the Korean Heart Study, aged 30-74 years, $1996-2011^{*}$

\begin{tabular}{|c|c|c|c|c|c|c|}
\hline & \multicolumn{3}{|c|}{ Men $(n=164$ 005) } & \multicolumn{3}{|c|}{ Women $(n=104310)$} \\
\hline & $\begin{array}{l}\text { Person-years } \\
\text { of follow-up }\end{array}$ & $\begin{array}{l}\text { Hard } \\
\text { CHD } \\
\text { eventst }\end{array}$ & $\begin{array}{l}\text { Incidence } \\
\text { per } 100000 \\
\text { PYף }\end{array}$ & $\begin{array}{l}\text { Person-years } \\
\text { of follow-up }\end{array}$ & $\begin{array}{l}\text { Hard } \\
\text { CHD } \\
\text { events }\end{array}$ & $\begin{array}{l}\text { Incidence } \\
\text { per } 100000 \\
\text { PYף }\end{array}$ \\
\hline Total† & 1961999 & 2086 & 121.1 & 1281102 & 510 & 52.1 \\
\hline \multicolumn{7}{|l|}{ Blood pressure } \\
\hline Normal & 683826 & 468 & 92.4 & 602146 & 91 & 25.9 \\
\hline $\begin{array}{l}\text { Stage-2 } \\
\text { hypertension }\end{array}$ & 131922 & 305 & 194.8 & 85253 & 119 & 94.2 \\
\hline \multicolumn{7}{|c|}{ Total cholesterol, mg/dL } \\
\hline$<160$ & 293873 & 173 & 81.4 & 213533 & 32 & 17.1 \\
\hline \multicolumn{7}{|c|}{ HDL-cholesterol, mg/dL } \\
\hline$<35$ & 157245 & 292 & 193.7 & 42652 & 28 & 59.6 \\
\hline $35-44$ & 618462 & 768 & 140.5 & 242097 & 128 & 63.5 \\
\hline $45-49$ & 438772 & 427 & 116.5 & 205596 & 107 & 71.2 \\
\hline $50-59$ & 523426 & 429 & 99.0 & 390158 & 144 & 45.0 \\
\hline$\geq 60$ & 224094 & 170 & 80.7 & 400598 & 103 & 36.6 \\
\hline \multicolumn{7}{|c|}{ LDL-cholesterol, mg/dL } \\
\hline$<100$ & 562674 & 372 & 82.7 & 385816 & 75 & 42.2 \\
\hline $100-129$ & 733988 & 661 & 106.6 & 463200 & 158 & 46.2 \\
\hline $130-149$ & 353968 & 447 & 138.9 & 217960 & 113 & 54.7 \\
\hline$\geq 150$ & 311369 & 606 & 195.2 & 214126 & 164 & 66.5 \\
\hline \multicolumn{7}{|l|}{ Smoking status } \\
\hline Current smoker & 1038830 & 1271 & 155.0 & 64612 & 38 & 88.0 \\
\hline Diabetes & 162348 & 399 & 217.7 & 75840 & 98 & 96.1 \\
\hline \multicolumn{7}{|c|}{$\begin{array}{l}\text { SI conversions: to convert HDL-C and TG to mmol/L, multiply by } 0.0259 . \\
\text { *Participants with risk factor at baseline (1996-2001). } \\
\text { †Mean ages of Korean were } 45.8 \text { years in men and } 47.6 \text { years in women, respectively. } \\
\text { ๆlncidences were standardized to the age distribution in the } 2005 \text { Korean population. } \\
\text { CHD, coronary heart disease; HDL, high-density lipoprotein; LDL, low-density lipoprotein; PY, person-years; TG, triglycerides. }\end{array}$} \\
\hline
\end{tabular}

basic model (to which it was superior). For women, model 3 was the best model on both criteria (AUC=0.815 and NRI=0.207). The second best model that reflects the women is model 1 (AUC $=0.812$ and $\mathrm{NRI}=0.177)$. The KRS was adopted from model 1 for both the sexes. The KRS algorithm is given in online supplementary appendix A.

\section{Comparison of the Framingham and the Korean risk} equations

Compared with the HRs from the KHS using the same variables, there were no big differences with the published HRs for Framingham, with the exception of LDL-cholesterol (table 5). The FRS overestimated, overall by a factor of six, the number of CHD events actually observed in the KHS. Figure 2 shows the agreement between the original and recalibrated Framingham function and the KRS in the KHS population. The KRS and recalibrated FRS are clearly in close agreement, as would be anticipated from table 5 .

\section{DISCUSSION}

The objectives of this study were (1) to develop a Korean CHD model; (2) to evaluate the ability of the FRS to 
Table 3 HRs for CHD risk factors in men in the Korean Heart Study, aged 30-74, 1996-2011

\begin{tabular}{|c|c|c|c|c|}
\hline & $\begin{array}{l}\text { Basic model } \\
\text { HR }(95 \% \mathrm{Cl})\end{array}$ & $\begin{array}{l}\text { Model } 1 \\
\text { HR (95\% Cl) }\end{array}$ & $\begin{array}{l}\text { Model } 2 \\
\text { HR }(95 \% \mathrm{Cl})\end{array}$ & $\begin{array}{l}\text { Model } 3 \\
\text { HR }(95 \% \mathrm{Cl})\end{array}$ \\
\hline Age & 1.13 (1.09 to 1.18$)$ & $1.13(1.08$ to 1.18$)$ & 1.13 (1.08 to 1.18$)$ & $1.13(1.08$ to 1.18$)$ \\
\hline \multicolumn{5}{|l|}{ Blood pressure } \\
\hline Normal & 1.00 & 1.00 & 1.00 & 1.00 \\
\hline Prehypertension & $1.30(1.16$ to 1.46$)$ & $1.29(1.15$ to 1.45$)$ & $1.32(1.17$ to 1.48$)$ & $1.28(1.14$ to 1.43$)$ \\
\hline Stage-1 hypertension & $1.74(1.53$ to 1.97$)$ & $1.72(1.52$ to 1.96$)$ & 1.78 (1.57 to 2.02$)$ & $1.68(1.48$ to 1.91$)$ \\
\hline Stage-2 hypertension & 2.22 (1.91 to 2.57$)$ & 2.20 (1.90 to 2.56$)$ & 2.28 (1.97 to 2.65$)$ & $2.13(1.84$ to 2.48$)$ \\
\hline \multicolumn{5}{|l|}{ Total cholesterol, mg/dL } \\
\hline$<160$ & 1.00 & 1.00 & 1.00 & 1.00 \\
\hline $160-199$ & 1.26 (1.07 to 1.49$)$ & 1.34 (1.14 to 1.59$)$ & 1.09 (0.90 to 1.32$)$ & 1.21 (1.02 to 1.43$)$ \\
\hline 200-239 & 1.81 (1.53 to 2.13$)$ & 2.02 (1.71 to 2.38$)$ & 1.23 (0.99 to 1.53$)$ & 1.67 (1.42 to 1.98$)$ \\
\hline $240-279$ & 2.42 (2.01 to 2.92$)$ & 2.77 (2.30 to 3.34$)$ & 1.34 (1.04 to 1.73$)$ & 2.19 (1.81 to 2.65$)$ \\
\hline$\geq 280$ & 3.79 (2.93 to 4.91$)$ & 4.45 (3.44 to 5.76$)$ & 2.02 (1.47 to 2.77$)$ & 3.37 (2.59 to 4.38$)$ \\
\hline \multicolumn{5}{|l|}{ Smoking } \\
\hline Never & 1.00 & 1.00 & 1.00 & 1.00 \\
\hline Former & 1.01 (0.88 to 1.16$)$ & $1.02(0.89$ to 1.17$)$ & $1.02(0.89$ to 1.17$)$ & $1.00(0.87$ to 1.15$)$ \\
\hline Current & 1.93 (1.72 to 2.17$)$ & 1.86 (1.65 to 2.09$)$ & 1.96 (1.75 to 2.21$)$ & 1.87 (1.66 to 2.11$)$ \\
\hline \multicolumn{5}{|l|}{ Diabetes } \\
\hline No & 1.00 & 1.00 & 1.00 & 1.00 \\
\hline Yes & 1.69 (1.51 to 1.89$)$ & 1.63 (1.46 to 1.82$)$ & 1.72 (1.53 to 1.92$)$ & 1.65 (1.48 to 1.85$)$ \\
\hline \multicolumn{5}{|l|}{ HDL-cholesterol, mg/dL } \\
\hline$<35$ & & 1.00 & & \\
\hline $35-44$ & & $0.66(0.57$ to 0.75$)$ & & \\
\hline $45-49$ & & 0.56 (0.48 to 0.65$)$ & & \\
\hline $50-59$ & & 0.45 (0.39 to 0.52$)$ & & \\
\hline$\geq 60$ & & $0.34(0.28$ to 0.41$)$ & & \\
\hline \multicolumn{5}{|l|}{ LDL-cholesterol, mg/dL } \\
\hline$<100$ & & & 1.00 & \\
\hline $100-129$ & & & $1.23(1.06$ to 1.43$)$ & \\
\hline $130-149$ & & & $1.50(1.25$ to 1.80$)$ & \\
\hline$\geq 150$ & & & 1.97 (1.61 to 2.40$)$ & \\
\hline \multicolumn{5}{|l|}{ Triglycerides, mg/dL } \\
\hline$<100$ & & & & 1.00 \\
\hline $100-149$ & & & & $1.21(1.07$ to 1.37$)$ \\
\hline $150-199$ & & & & 1.35 (1.18 to 1.54$)$ \\
\hline $200-249$ & & & & 1.39 (1.19 to 1.63$)$ \\
\hline$\geq 250$ & & & & 1.30 (1.11 to 1.52$)$ \\
\hline $\mathrm{ROC}(95 \% \mathrm{Cl})$ & $0.756(0.745$ to 0.766$)$ & $0.764(0.752$ to 0.774$)$ & 0.758 (0.747 to 0.769$)$ & 0.757 (0.746 to 0.768$)$ \\
\hline Continuous NRI (95\% Cl) & Referent model & $0.284(0.231$ to 0.339$)$ & $0.185(0.124$ to 0.246$)$ & 0.109 (0.051 to 0.162$)$ \\
\hline
\end{tabular}

predict the 10-year CHD risk in the Korean population. Over 2700 first CHD events occurred in this cohort of over 268000 Koreans in 11.6 years. The KRS was developed based on these data. When compared with the actual CHD cases, the KRS performed well, but not substantially better than a recalibrated version of the FRS.

Estimation of absolute risk required for treatment and for prevention of CHD commonly relies on prediction models developed from the experience of prospective cohort studies. $^{8-10} 21$ Although prediction algorithms developed by the Framingham investigators have been widely adopted to formulate clinical guidelines in the USA and elsewhere, ${ }^{21}$ the Framingham functions have overestimated the CHD risk in some populations, leading to a concern that it may not be appropriate to other populations. ${ }^{3-68}$ In our study, the FRS also overestimated the risk of CHD in the Korean population, where CHD incidence is relatively low. Another factor of relevance is the inclusion of softer CHD end points in the derivation of the FRS than we used in deriving the KHS.

Several studies ${ }^{3}{ }^{6}$ have examined CHD events in the Framingham Heart Study (FHS). Due to problems anticipated risk Framingham, Ahn et $a l^{7}$ previously suggested the need for Korean guidelines for the management of CHD to avoid artificial inflation of costs in primary prevention. 
Table 4 HRs for CHD risk factors in women in the Korean Heart Study, aged 30-74, 1996-2011

\begin{tabular}{|c|c|c|c|c|}
\hline & $\begin{array}{l}\text { Basic model } \\
\text { HR }(95 \% \mathrm{Cl})\end{array}$ & $\begin{array}{l}\text { Model } 1 \\
\text { HR (95\% Cl) }\end{array}$ & $\begin{array}{l}\text { Model } 2 \\
\text { HR }(95 \% \mathrm{Cl})\end{array}$ & $\begin{array}{l}\text { Model } 3 \\
\text { HR }(95 \% \mathrm{Cl})\end{array}$ \\
\hline Age & $1.14(1.03$ to 1.26$)$ & $1.13(1.02$ to 1.24$)$ & $1.14(1.03$ to 1.26$)$ & $1.12(1.01$ to 1.24$)$ \\
\hline \multicolumn{5}{|l|}{ Blood pressure } \\
\hline Normal & 1.00 & 1.00 & 1.00 & 1.00 \\
\hline Prehypertension & 1.61 (1.24 to 2.09$)$ & 1.57 (1.21 to 2.04$)$ & 1.61 (1.32 to 2.09$)$ & 1.54 (1.19 to 2.01$)$ \\
\hline Stage-1 hypertension & $2.01(1.52$ to 2.66$)$ & $1.93(1.46$ to 2.56$)$ & 2.01 (1.52 to 2.66$)$ & $1.88(1.42$ to 2.50$)$ \\
\hline Stage-2 hypertension & 3.15 (2.35 to 4.21$)$ & 3.02 (2.26 to 4.05$)$ & 3.15 (2.36 to 4.22$)$ & 2.90 (2.17 to 3.89$)$ \\
\hline \multicolumn{5}{|l|}{ Total cholesterol, mg/dL } \\
\hline$<160$ & 1.00 & 1.00 & 1.00 & 1.00 \\
\hline $160-199$ & 1.17 (0.80 to 1.72$)$ & $1.26(0.86$ to 1.86$)$ & $1.10(0.71$ to 1.69$)$ & $1.12(0.76$ to 1.65$)$ \\
\hline 200-239 & 1.45 (0.99 to 2.12$)$ & 1.62 (1.10 to 2.38$)$ & 1.29 (0.79 to 2.10$)$ & 1.31 (0.87 to 2.00$)$ \\
\hline $240-279$ & 1.53 (1.01 to 2.31$)$ & 1.77 (1.16 to 2.68$)$ & 1.36 (0.78 to 2.38$)$ & 1.32 (0.87 to 2.00$)$ \\
\hline$\geq 280$ & 2.38 (1.48 to 3.82$)$ & $2.78(1.72$ to 4.50$)$ & $2.12(1.14$ to 3.95$)$ & $1.96(1.21$ to 3.18$)$ \\
\hline \multicolumn{5}{|l|}{ Smoking } \\
\hline Never & 1.00 & 1.00 & 1.00 & 1.00 \\
\hline Former & $1.17(0.78$ to 1.77$)$ & $1.20(0.79$ to 1.80$)$ & $1.17(0.78$ to 1.77$)$ & $1.19(0.79$ to 1.80$)$ \\
\hline Current & 2.06 (1.47 to 2.87$)$ & 2.00 (1.43 to 2.79$)$ & 2.06 (1.48 to 2.88$)$ & 1.95 (1.39 to 2.72$)$ \\
\hline \multicolumn{5}{|l|}{ Diabetes } \\
\hline No & 1.00 & 1.00 & 1.00 & 1.00 \\
\hline Yes & 1.96 (1.57 to 2.45$)$ & 1.89 (1.51 to 2.37$)$ & 1.96 (1.57 to 2.46$)$ & 1.84 (1.47 to 2.30$)$ \\
\hline \multicolumn{5}{|l|}{ HDL-cholesterol, mg/dL } \\
\hline$<35$ & & 1.00 & & \\
\hline $35-44$ & & $0.79(0.52$ to 1.19$)$ & & \\
\hline $45-49$ & & $0.86(0.56$ to 1.31$)$ & & \\
\hline $50-59$ & & $0.66(0.44$ to 1.00$)$ & & \\
\hline$\geq 60$ & & $0.51(0.33$ to 0.78$)$ & & \\
\hline \multicolumn{5}{|l|}{ LDL-cholesterol, mg/dL } \\
\hline$<100$ & & & 1.00 & \\
\hline $100-129$ & & & $1.11(0.80$ to 1.54$)$ & \\
\hline $130-149$ & & & $1.16(0.79$ to 1.72$)$ & \\
\hline$\geq 150$ & & & $1.13(0.74$ to 1.74$)$ & \\
\hline \multicolumn{5}{|l|}{ Triglyceride, mg/dL } \\
\hline$<100$ & & & & 1.00 \\
\hline $100-149$ & & & & $1.19(0.93$ to 1.51$)$ \\
\hline $150-199$ & & & & 1.61 (1.23 to 2.09$)$ \\
\hline $200-249$ & & & & 2.13 (1.58 to 2.89$)$ \\
\hline$\geq 250$ & & & & 1.63 (1.17 to 2.27$)$ \\
\hline $\mathrm{ROC}(95 \% \mathrm{Cl})$ & 0.809 (0.789 to 0.829$)$ & $0.812(0.792$ to 0.833$)$ & 0.809 (0.789 to 0.829$)$ & $0.815(0.795$ to 0.835$)$ \\
\hline Continuous NRI (95\% Cl) & Referent model & 0.177 (0.043 to 0.313$)$ & 0.160 (0.019 to 0.295$)$ & 0.207 (0.087 to 0.336$)$ \\
\hline
\end{tabular}

To compare the CHD risk factors in men and women in the KHS to those in the FHS, the same six variables that were examined in the FHS paper were analysedage (year), blood pressure ( $\mathrm{mm} \mathrm{Hg})$, TC (mg/dL), HDL-C $(\mathrm{mg} / \mathrm{dL})$, diabetes and smoking. The FHS did not yield significant HDL-C $\geq 60 \mathrm{mg} / \mathrm{dL}$ results for men (RR, $0.63,95 \%$ CI 0.34 to 1.18 ) and women (RR, 0.58, $95 \%$ CI 0.33 to 1.02). ${ }^{6}{ }^{21}$ In Korean men, however, $11 \%$ had HDL-C $\geq 60 \mathrm{mg} / \mathrm{dL}$ (RR, $0.33,95 \%$ CI 0.28 to 0.41 ), a $66 \%(\mathrm{RR}, 0.34)$ decrease in risk compared with KHS men with HDL-C $<35 \mathrm{mg} / \mathrm{dL}$. The considerable reduction of CHD risk in participants with higher HDL-C levels reinforces the need for Korean populations to monitor their cholesterol levels closely.
Hippisley-Cox et $a t^{22}$ also developed, validated and evaluated a new QRISK model to estimate lifetime risk of CVD in the UK. This model was made in light of the emergence of a new cardiovascular risk prediction tool, which was shown to have greater predictive ability than the Framingham risk equation. ${ }^{23}$ Without recalibration they urge caution in using the FRS to identify high risk patients in the UK. Recently, the key issue is the extent of reallocation. Allocation is critically dependent on the cardiovascular risk score used and its performance in contemporaneous, ethnically diverse UK populations. ${ }^{24}$

The strengths of this cohort study include a large sample size, a wide age range and a nationally representative sample. The KHS cohort consisted of 268315 
Table 5 HRs of coronary events in Framingham and Korean studies in men and women

\begin{tabular}{|c|c|c|c|c|c|c|}
\hline & \multicolumn{3}{|l|}{ Men } & \multicolumn{3}{|l|}{ Women } \\
\hline & $\begin{array}{l}\text { Framingham } \\
\text { Heart Study }\end{array}$ & $\begin{array}{l}\text { Korean Heart } \\
\text { Study }\end{array}$ & p Value & $\begin{array}{l}\text { Framingham } \\
\text { Heart Study }\end{array}$ & $\begin{array}{l}\text { Korean Heart } \\
\text { Study }\end{array}$ & p Value \\
\hline Age (year) & $1.05(1.04-1.06)$ & $1.07(1.06-1.07)$ & 0.0040 & $1.04(1.03-1.06)$ & $1,09(1.08-1.11)$ & $<0.0001$ \\
\hline \multicolumn{7}{|c|}{ Blood pressure $(\mathrm{mm} \mathrm{Hg})$} \\
\hline Optimal+normal & 1.00 & 1.00 & & 1.00 & 1.00 & \\
\hline High normal & $1.32(0.98-1.78)$ & $1.28(1.13-1.45)$ & 0.8352 & $1.34(0.88-2.05)$ & $1.40(1.07-1.83)$ & 0.8659 \\
\hline Stage 1 & $1.73(1.32-2.26)$ & $1.62(1.46-1.81)$ & 0.6668 & $1.75(1.21-2.54)$ & $1.65(1.31-2.09)$ & 0.7907 \\
\hline Stage $2-4$ & $1.92(1.36-2.24)$ & $2.10(1.83-2.40)$ & 0.6409 & $2.19(1.46-3.27)$ & $2.61(2.04-3.34)$ & 0.4701 \\
\hline \multicolumn{7}{|c|}{ LDL-cholesterol (mg/dL) } \\
\hline$<130$ & 1.00 & 1.00 & & 1.00 & 1.00 & \\
\hline $130-159$ & $1.19(0.91-1.54)$ & $1.56(1.42-1.73)$ & 0.0611 & $1.24(0.84-1.81)$ & $1.24(1.01-1.53)$ & 0.9931 \\
\hline$\geq 160$ & $1.74(1.36-2.34)$ & 2.34 (2.09-2.62) & 0.0326 & $1.68(1.17-2.40)$ & $1.43(1.14-1.79)$ & 0.4602 \\
\hline \multicolumn{7}{|c|}{ HDL-cholesterol (mg/dL) } \\
\hline$<35$ & $1.46(1.15-1.85)$ & $1.68(1.48-1.90)$ & 0.3092 & $2.08(1.33-3.25)$ & $1.25(0.85-1.84)$ & 0.0911 \\
\hline $35-59$ & 1.00 & 1.00 & & 1.00 & 1.00 & \\
\hline$\geq 60$ & $0.61(0.41-0.91)$ & $0.66(0.57-0.78)$ & 0.7080 & $0.64(0.47-0.87)$ & $0.72(0.58-0.89)$ & 0.5517 \\
\hline Smoking (yes/no) & $1.71(1.39-2.10)$ & 1.89 (1.72-2.07) & 0.3917 & 1.49 (1.13-1.97) & 1.95 (1.40-2.72) & 0.2230 \\
\hline Diabetes (yes/no) & $1.47(1.04-2.08)$ & $1.71(1.53-1.91)$ & 0.4182 & $1.80(1.18-2.74)$ & $1.96(1.57-2.45)$ & 0.7276 \\
\hline
\end{tabular}
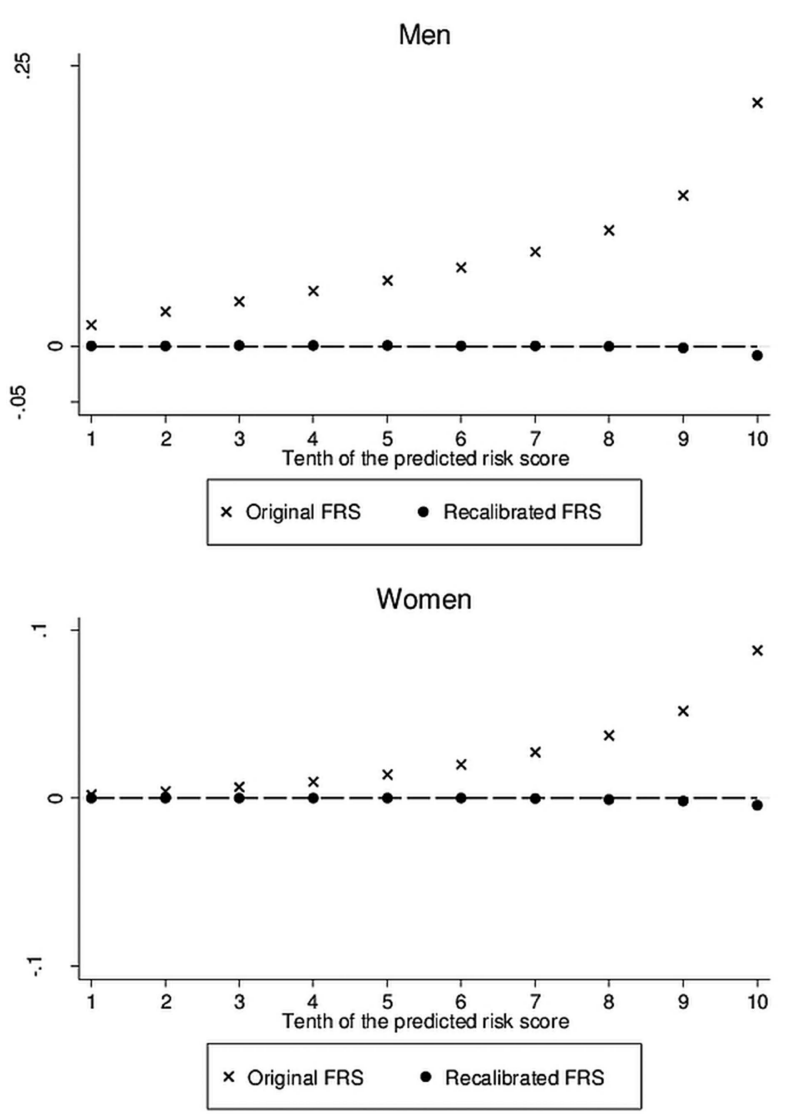

Figure 2 Agreement between both the original and recalibrated Framingham risk scores and the Korean risk score for coronary heart disease, by 10th of the predicted risks from the Korean risk score. participants aged 30-74 years, which was compared to 5251 participants aged 30-74 in the FHS. Examination of alternative lipid variables, triglycerides and LDL-cholesterol, and finer classification of smoking habits to include former smokers, strengthens this study. Moreover, discrimination, calibration and reclassification are all considered here, using contemporary methods. ${ }^{19}$ The limitations of this study include possible measurement errors. Clinical data from the health promotion centres were one-time measurements of blood pressure and medical examinations. Also, participants might have under-reported the smoking status and alcohol consumption in the self-report questionnaires. In addition, the validation study on mortality data has not been conducted.

In conclusion, we developed a CHD prediction model for Koreans and compared the estimates from the model with the actual CHD cases. This new model provides an accurate prediction of the risk of CHD among Korean. With the gradual rise in CHD events among Koreans, the prevention and treatment of CHD risk factors such as hypertension, hypercholesterolaemia and diabetes are important public health concerns.

\section{Author affiliations}

${ }^{1}$ Department of Epidemiology and Health Promotion, and Institute for Health Promotion, Graduate School of Public Health, Yonsei University, Seoul, Republic of Korea

${ }^{2}$ Severance Cardiovascular Hospital, Yonsei University Health System, Seoul, Republic of Korea

${ }^{3}$ Cardiovascular Center, Korea University Guro Hospital, Seoul,

Republic of Korea

${ }^{4}$ Department of Internal Medicine, Seoul National University College of Medicine, Seoul, Republic of Korea 
${ }^{5}$ Division of Cardiology, Department of Medicine, Samsung Medical Center, Sungkyunkwan University School of Medicine, Seoul, Republic of Korea ${ }^{6}$ Division of Cardiology, Department of Medicine, Asan Medical Center, University of Ulsan College of Medicine, Seoul, Republic of Korea

${ }^{7}$ Department of Internal Medicine, The Catholic University of Korea, School of Medicine, Seoul, Republic of Korea

${ }^{8}$ Health Insurance Policy Research Institute, National Health Insurance Service, Seoul, Republic of Korea

${ }^{9}$ Department of Family Medicine, Yonsei University College of Medicine, Seoul, Republic of Korea

${ }^{10}$ Seoul National University College of Medicine, Bundang Hospital, Sungnam, Republic of Korea

${ }^{11}$ Department of Family Medicine, CHA Bundang Medical Center, CHA University, Sungnam, Republic of Korea

${ }^{12}$ Division of Cardiology, Department of Internal Medicine, Center for Health Promotion, Samsung Medical Center, Sungkyunkwan University School of Medicine, Seoul, Republic of Korea

${ }^{13}$ Department of Family Medicine, Health Promotion Center, Seoul National University Hospital, Seoul, Republic of Korea

${ }^{14}$ Department of Family Medicine, Daejeon Sun General Hospital, Daejeon, Republic of Korea

${ }^{15}$ Department of Family Medicine, Konyang University Hospital, Daejeon, Republic of Korea

${ }^{16}$ Department of Preventive Medicine and Public Health, College of Medicine, Chungnam National University, Daejeon, Republic of Korea

${ }^{17}$ Department of Family Medicine, School of Medicine, Chungnam National University, Daejeon, Republic of Korea

${ }^{18}$ Department of Occupational and Environmental Medicine, College of Medicine, Soonchunhyang University, Cheonan, Republic of Korea

${ }^{19}$ Department of Occupational and Environmental Medicine, Daejeon Eulji University Hospital, Daejeon, Republic of Korea

${ }^{20}$ Department of Family Medicine, Daegu Catholic University Hospital, Daegu, Republic of Korea

${ }^{21}$ Department of Preventive Medicine, Yonsei University Wonju College of Medicine, Wonju, Republic of Korea

${ }^{22}$ Institute of Genomic Cohort, Yonsei University Wonju College of Medicine, Wonju, Republic of Korea

${ }^{23}$ Department of Family Practice and Community Health, Ajou University School of Medicine, Suwon, Republic of Korea

${ }^{24}$ Department of Preventive Medicine, Ajou University School of Medicine, Suwon, Republic of Korea

${ }^{25}$ Department of Occupational and Environmental Medicine, Ulsan University Hospital, University of Ulsan College of Medicine, Ulsan, Korea

${ }^{26}$ Department of Family Medicine, Ulsan University Hospital, University of Ulsan College of Medicine, Ulsan, South Korea

${ }^{27}$ The Health Screening and Promotion Center, Asan Medical Center, Seoul, Republic of Korea

${ }^{28}$ Department of Family Medicine, Dong-A University Medical Center, Busan, Republic of Korea

${ }^{29}$ Department of Preventive Medicine and Public Health, Yonsei University

College of Medicine, Seoul, Republic of Korea

${ }^{30}$ Korea Medical Institute, Seoul, Republic of Korea

${ }^{31}$ Nuffield Department of Population Health, The George Institute for Global Health, University of Oxford, Oxford, UK

${ }^{32}$ The George Institute for Global Health, University of Sydney, Sydney,

Australia

${ }^{33}$ Department of Epidemiology, Johns Hopkins Bloomberg School of Public Health, Baltimore, Maryland, USA

Acknowledgements The authors thank the staff of the Korean National Health Insurance Service.

Contributors Data analysis was undertaken by SHJ, YM and KJJ. The article was drafted by SHJ, YJ, MW and YM. SHJ, YJ, DJO, B-HO, SHL, S-WP, K-BS, YM, KJJ, HK, YDY, SJB, DCL, SHC, MJK, JS, BLC, ESK, B-YY, T-YL, JSK, Y-JL, J-KO, SHK, J-KP, SBK, SBP, SYL, C-IY, MCK, H-KK, J-sP, HCK, GJL and MW substantially contributed to the conception or design of the work, revising the work, approved the final version to be published, and agreed to be accountable for all aspects of the work in ensuring that questions related to the accuracy or integrity of any part of the work are appropriately investigated and resolved.
Funding This study was funded by Seoul City R\&BD programme (10526) and by a grant of the Korean Health Technology R\&D Project, Ministry of Health \& Welfare, Republic of Korea (HI13C0715)

Competing interests None.

Ethics approval The Institutional Review Board of Human Research of Yonsei University and all the health promotion centres that participated in the KHS approved the study. We used the physical examination data.

Provenance and peer review Not commissioned; externally peer reviewed.

Data sharing statement No additional data are available.

Open Access This is an Open Access article distributed in accordance with the Creative Commons Attribution Non Commercial (CC BY-NC 3.0) license, which permits others to distribute, remix, adapt, build upon this work noncommercially, and license their derivative works on different terms, provided the original work is properly cited and the use is non-commercial. See: http:// creativecommons.org/licenses/by-nc/3.0/

\section{REFERENCES}

1. World Health Organization. Cardiovascular diseases (CVDs) [Data file]. Retrieved from http://www.who.int/mediacentre/factsheets/fs317/ en/index.html

2. National Bureau of Statistics, Republic of Korea. Annual report on the cause of death statistics. Seoul, Republic of Korea, 2011.

3. Hense $\mathrm{H}$, Schulte $\mathrm{H}$, Lowel $\mathrm{H}$, et al. Framingham risk function overestimates risk of coronary heart disease in men and women from Germany-results from the MONICA Augsburg and the PROCAM cohorts. Eur Heart J 2003;24:937-45.

4. Empana JP, Tafflet M, Escolano S, et al. Predicting CHD risk in France: a pooled analysis of the D.E.S.I.R., three city, PRIME, and SU.VI.MAX studies. Eur J Cardiol Prev Rehabil 2011;1:175-85.

5. Vergnaud AC, Bertrais $S$, Galan $P$, et al. Ten-year risk prediction in French men using the Framingham coronary score: results from the national SU.VI.MAX cohort. Prev Med 2008;47:61-5.

6. Liu J, Hong Y, D'Agostino R, et al. Predictive value for the Chinese population of the Framingham $\mathrm{CHD}$ risk assessment tool compared with the Chinese multi-provincial cohort study. JAMA 2004;291:2591-9.

7. Ahn KA, Yun JE, Cho ER, et al. Framingham equation model overestimates risk of ischemic heart disease in Korean men and women. Korean J Epidemiol 2006;28:162-70.

8. Woodward $\mathrm{M}$, Brindle $\mathrm{P}$, Tunstall-Pedoe $\mathrm{H}$. Adding social deprivation and family history to cardiovascular risk assessment: the ASSIGN score from the Scottish Heart Health Extended Cohort (SHHEC). Heart 2007;93:172-6.

9. Woodward M, Tunstall-Pedoe H, Rumley A, et al. Does fibrinogen add to prediction of cardiovascular disease? Results from the Scottish Heart Health Extended Cohort Study. Br J Haematol 2009;146:442-6.

10. Tzoulaki I, Liberopoulos $\mathrm{G}$, loannidis JPA. Assessment of claims of improved prediction beyond the Framingham risk score. JAMA 2009;302:2345-52.

11. Wilson P, D'Agostino R, Levy D, et al. Prediction of coronary heart disease using risk factor categories. Circulation 1998;97:1837-47.

12. Jee $\mathrm{SH}$, Batty $\mathrm{GB}$, Jang $\mathrm{Y}$, et al. The Korean heart study: rationale objectives, protocol, and preliminary results for a new prospective cohort study of 430,920 men and women. Eur J Prev Cardiol 2013. [Epub ahead of print]

13. Kim HK, Kim $\mathrm{CH}$, Kim EH, et al. Impaired fasting glucose and risk of cardiovascular disease in Korean men and women: the Korean Heart Study. Diabetes Care 2013;36:328-35.

14. Kimm H, Yun JE, Lee SH, et al. Validity of the diagnosis of acute myocardial infarction in Korean national medical health insurance claims data: the Korean Heart Study (1). Korean Circ J 2012;42:10-15.

15. Kim HY. Validity of the diagnosis of acute myocardial infarction in Korean national medical health insurance claims data: the Korean Heart Study [Master thesis]. Yonsei University, Seoul, Korea, June 2013.

16. Chobanian AV, Bakris GL, Black HR, et al. National Heart, Lung, and Blood Institute Joint National Committee on Prevention, Detection, Evaluation, and Treatment of High Blood Pressure National High Blood Pressure Education Program Coordinating Committee. The seventh report of the Joint National Committee on Prevention, Detection, Evaluation, and Treatment of High Blood Pressure: the JNC 7 report. JAMA 2003;289:2560-72. 
17. World Health Organization. Diabetes Mellitus: Report of a WHO Study Group. Geneva, Switzerland: World Health Organization, 1985; Technical report series 727 .

18. Pencina MJ, D'Agostino RB. Overall C as a measure of discrimination in survival analysis: model specific population value and confidence interval estimation. Stat Med 2004;23:2109-23.

19. Woodward M. Epidemiology: study design and data analysis. 3rd edn. Boca Raton: CRC Press, 2014.

20. Nam B-H. Discrimination and calibration in survival analysis [dissertation]. Boston, MA, Boston University, 2000.

21. D'Agostino R, Grundy S, Sullivan L, et al. Validation of the Framingham coronary heart disease prediction scores results of a multiple ethnic groups investigation. JAMA 2001;286:

180-7.

22. Hippisley-Cox J, Coupland C, Vinogradova $Y$, et al. Derivation and validation of QRISK, a new cardiovascular disease risk score for the United Kingdom: prospective open cohort study. BMJ 2007;335:136

23. Collins GS, Altman DG. An independent and external validation of QRISK2 cardiovascular disease risk score: a prospective open cohort study. BMJ 2010;340:c2442.

24. Hippisley-Cox J, Coupland C, Robson J, et al. Advantages of QRISK2 (2010): the key issue is ethnicity and extent of reallocation. Heart 2011:97:515. 